\title{
Comparative Study of the Analgesic Efficacy of Rectal Tramadol versus Intravenous Tramadol for Inguinal Hernia Repair Surgery
}

\author{
Jose B Cherayath ${ }^{1}$, Jitin George ${ }^{2}$ \\ ${ }^{1}$ Associate Professor, Department of Anaesthesia, P K Das Medical College, Vaniyamkulam, Ottapalam, Palakkad, Kerala-679522, ${ }^{2}$ Assistant Professor, \\ Department of Anaesthesia, P K Das Medical College, Vaniyamkulam, Ottapalam, Palakkad, Kerala-679522.
}

\section{Abstract}

Background: There is uncertainity observed in selection of optimal method for intra and post operative administration of analgesics for inguinal hernia repair surgery. Aim: This study was performed to evaluate and differentiate the analgesic efficacy of tramadol via intravenous and rectal administration for inguinal hernia repair. Subjects and Methods: This study is a prospective, randomised, hospital based, single blinded study. All 50 patients were divided into 2 groups of 25 each namely group A and Group B. Group A received intravenous tramadol hydrochloride $(1.5 \mathrm{mg} / \mathrm{kg})$ and group B received tramadol $(1.5 \mathrm{mg} / \mathrm{kg})$ in the form of suppository. Results: In the rectally administered tramadol, the analgesia duration is prolonged which further reduces the rescue analgesia requirement. Compared to intravenously administered tramadol, patient comfort is more in rectally administered tramadol as nausea and vomiting postoperatively is avoided. Conclusion: This study concludes that rectally administering tramadol is safer, easier, more reliable, non-invasive, more comfortable and painless compared to intravenously administered tramadol.

Keywords: Inguinal hernia, Postoperative analgesia.

Corresponding Author: Dr. Jitin George, Assistant Professor, Department of Anaesthesia, P K Das Medical College, Vaniyamkulam, Ottapalam, Palakkad, Kerala-679522.

Received: November 2019

Accepted: November 2019

\section{Introduction}

Pain is caused by actual or potential damage and is an unpleasant sensory and emotional experience of differing intensity. For inguinal hernia repair surgery, the suitable method for intra and post-operative analgesia is uncertain. ${ }^{[1]}$ Tramadol hydrochloride is a centrally acting opioid analgesic and it acts on mu opioid receptors and according to WHO pain score, is called phase II analgesic. It has mixed opioid and non-opioid activities. In the central nervous system, through $\alpha-2$ agonist and serotonergic activity, the non-opioid part is mediated and inhibits reuptake of norepinephrine and 5-hydroxytryptamine and displaces the stored 5-HT from the nerve endings. ${ }^{[2,3]}$ This study was performed to evaluate and differentiate the analgesic efficacy of tramadol via intravenous and rectal administration for inguinal hernia repair. However, peak concentrations are reached rapidly after intravenous and oral administration, and it is associated with post-operative nausea and vomiting. Intravenous tramadol as a post-operative analgesic is restricted in day surgery and inguinal hernia repair to avoid nausea and vomiting. ${ }^{[4,5]}$ Rectal administration of tramadol can be used as an alternative. Its advantage is it is convenient to use and is well established treatment for post-operative pain in adults. The absorption of tramadol rectally has proven to be low variable. By stimulating the mu opioid receptors, O- demethylated metabolite (M1) contributes to analgesic effect. In treating acute and post-operative chronic pain of severe intensity, tramadol is used.

\section{Subjects and Methods}

This study is a prospective, randomised, hospital based, single blinded study. The institutional ethical committee clearance was obtained and adult patients of ASA grade I and II who were posted for inguinal hernia repair were included in the study. Patients who had history of allergy to any drug, old age, obesity, who were on monoamine oxidase inhibitors, anorectal complaints or other systemic diseases like cardiovascular, neurological, respiratory, hepatic or renal were excluded from the study. Visual analog scale (VAS) scoring system procedure was explained to all the patients prior to surgery. VAS consisted of a $10 \mathrm{~cm}$ line with $0 \mathrm{~cm}$ means no pain and $10 \mathrm{~cm}$ means worst pain. Using VAS scale, pain was measured. After written informed consent was obtained, all 50 patients were divided into 2 groups of 25 each namely group A and Group B.

Group A received intravenous tramadol hydrochloride (1.5 $\mathrm{mg} / \mathrm{kg})$ and group B received tramadol $(1.5 \mathrm{mg} / \mathrm{kg})$ in the form of suppository.

Premedication of inj. Glycopyrrolate $0.004 \mathrm{mg} / \mathrm{kg}$ i.v. and inj. Midazolam $0.02 \mathrm{mg} / \mathrm{kg}$ i.v. $10 \mathrm{~min}$ was administered to all the patients prior to induction. $100 \%$ O2 for $3 \mathrm{~min}$, 
induction with inj. Sodium Thiopentone $5 \mathrm{mg} / \mathrm{kg}$ i.v., followed by nj.Atracurium IV $0.5 \mathrm{mg} / \mathrm{Kg}$ body weight. and intubation with an appropriate-sized oral, cuffed, portex endotracheal tube in the preoxygenation first attempt was successful in all the patients. In Group A patients, intravenous tramadol hydrochloride injection $1.5 \mathrm{mg} / \mathrm{kg}$ was given immediately after induction while Group B patients received tramadol hydrochloride suppository $1.5 \mathrm{mg} / \mathrm{kg}$ via the rectal route. This was taken as $0 \mathrm{~h}$. With $66 \% \mathrm{~N} 2 \mathrm{O}$ in $33 \% \mathrm{O} 2$ and inj. Vecuronium Bromide with a loading dose of $0.1 \mathrm{mg} / \mathrm{kg}$ and maintenance of $0.02 \mathrm{mg} / \mathrm{kg}$, anesthesia was maintained and IPPV via circle system was given. The following parameters were recorded namely pulse rate, blood pressure, spo2 intraoperatively. When hemostasis was confirmed and when all the criteria for extubation were fulfilled, reversal with inj. Neostigmine $0.05 \mathrm{mg} / \mathrm{kg}$ and inj. Glycopyrrolate $0.008 \mathrm{mg} / \mathrm{kg}$ was given, after completion of surgery. Patients were kept under observation in the ward. To avoid postoperative nausea and vomiting, before extubation, inj. Ondansetron $0.08 \mathrm{mg} / \mathrm{kg}$ i.v. was given slowly as a prophylactic measure. Assessment was done at $0,0.25,0.5$, $1,2,4,6,8,10,12,18,20$ and $24 \mathrm{~h}$. The surgery duration was 30-60 min. A blinded ward nurse recorded postoperative pain according to the VAS, pulse rate and blood pressure, nausea, vomiting, need for rescue analgesics and local burning. Rescue analgesic in the form of intravenous Dynapar-AQ (Diclofenac sodium) $75 \mathrm{mg}$ diluted with $100 \mathrm{ml}$ normal saline was given, when the score was $\geq 3$ by VAS. Results were expressed as mean with standard deviation. Paired t-test was used for statistical analysis. $\mathrm{P}$ value of lesser than 0.05 was considered to be significant and $P$ value of lesser than 0.001 was considered to be highly significant.

\section{Results}

Table 1: Demographic data

Table 1: Demographic data
\begin{tabular}{|l|l|l|l|}
\hline Demographic Data & Mean (Range) & P value \\
\cline { 2 - 3 } & Group A & Group B & \\
\hline No. of patients & 25 & 25 & \\
\hline Sex (M/F) & $19 / 6$ & $17 / 8$ & \\
\hline Age in years & $\begin{array}{l}18.54(18- \\
25)\end{array}$ & $18.65(21-26)$ & 0.65 \\
\hline Weight in kgs & $\begin{array}{l}50.47(54- \\
69)\end{array}$ & $50.95(49-71)$ & 0.78 \\
\hline $\begin{array}{l}\text { Length of operation } \\
\text { (min) }\end{array}$ & $\begin{array}{l}50.84(30- \\
60)\end{array}$ & $45.11(42-65)$ & 0.05 \\
\hline
\end{tabular}

Table 2: VAS in intravenous tramadol.

\begin{tabular}{|l|l|l|l|l|l|l|l|l|l|l|}
\hline \multicolumn{1}{|l|}{ VAS } & \multicolumn{1}{|c|}{ Time in hours } \\
\hline \multicolumn{1}{|l|}{} & $\mathbf{1}$ & $\mathbf{2}$ & $\mathbf{4}$ & $\mathbf{6}$ & $\mathbf{8}$ & $\mathbf{1 0}$ & $\mathbf{1 2}$ & $\mathbf{1 8}$ & $\mathbf{2 0}$ & $\mathbf{2 4}$ \\
\hline \multicolumn{1}{|l|}{ Number of patients } \\
\hline 0 & 17 & 17 & 11 & 2 & 15 & 14 & 12 & 11 & 21 & 22 \\
\hline 1 & 6 & 6 & 6 & 4 & 4 & 4 & 5 & 2 & 3 & 2 \\
\hline 2 & 2 & 2 & 7 & 5 & 2 & 3 & 8 & 2 & 1 & 1 \\
\hline 3 & 0 & 0 & 1 & 14 & 4 & 4 & 0 & 10 & 0 & 0 \\
\hline
\end{tabular}

Table 3: VAS in suppository of tramadol.

\begin{tabular}{|c|c|c|c|c|c|c|c|c|c|c|}
\hline \multicolumn{3}{|c|}{ VAS } & \multicolumn{8}{|c|}{ Time in hours } \\
\hline & $\mathbf{1}$ & 2 & 4 & 6 & 8 & 10 & 12 & 18 & 20 & 24 \\
\hline \multicolumn{11}{|c|}{ Number of patients } \\
\hline 0 & 23 & 23 & 22 & 15 & 8 & 20 & 20 & 21 & 18 & 23 \\
\hline 1 & 2 & 2 & 2 & 1 & 1 & 2 & 1 & 2 & 4 & 2 \\
\hline 2 & 0 & 0 & 1 & 8 & 1 & 2 & 3 & 2 & 0 & 0 \\
\hline 3 & 0 & 0 & 0 & 1 & 15 & 1 & 1 & 0 & 3 & 0 \\
\hline
\end{tabular}

[Table 1] shows that male to female was 19:6 in group A and 17:8 in group B. Age in years was 18.54 in group A and in group $\mathrm{B}$, it was 18.65 . Weight in $\mathrm{kgs}$ was 50.47 in group $\mathrm{A}$ and in group B, it was 50.95. Length of operation was longer in Group A when compared to Group B.

Table 4: Duration of analgesia in minutes.

\begin{tabular}{|l|l|}
\hline Group A $($ mean \pm SD) & Group B $($ mean \pm SD $)$ \\
\hline $440 \pm 89.35$ & $510 \pm 143.28$ \\
\hline
\end{tabular}

\section{Discussion}

The tramadol role is evaluated in this study by two different routes in inguinal hernia repair. Psychological trauma resulting in uncooperative patients is associated with postoperative pain. Post-operative nausea and vomiting is observed after intravenous and oral administration resulting in maximum peak concentrations rapidly. Rectal administration of tramadol is an alternative to postoperative analgesic during day surgery. It is convenient to use rectal tramadol in adults as it is easy to administer in adults. Giorgi $\mathrm{M}$ et al. ${ }^{[6]}$ conducted a study in which on the basis of mono and bi-compartmental models, plasma concentrations after rectal and intravenous administration were fitted respectively. Following rectal administration tramadol was detected from 5 minutes up to 10 hours, in lesser amounts than M5 and M2, while M1 was detected in negligible amounts. Following I/V administration tramadol was detected up to 10 hours, M2 and M5 were detected at similar concentrations, and M1 was present at low concentrations. The area under the curve (AUC) of the three metabolites did not differ significantly after either route of administration of tramadol. The absolute bioavailability of tramadol via rectal administration was 10 (SD 4)\%. Gadani $\mathrm{HN}$ et al, ${ }^{[7]}$ reported that forty adult patients of ASA grade 1 and 2 posted for tonsillectomy were randomized to receive either intravenous tramadol $(1.5 \mathrm{mg} / \mathrm{kg})(\mathrm{n}=20)$ Group A or rectal tramadol $(1.5 \mathrm{mg} / \mathrm{kg})$, maximum $100 \mathrm{mg}(\mathrm{n}=20)$, Group B immediately after the induction of anesthesia. Pain measurement was performed using visual analogue scale. Rescue analgesia was given when the VAS was $\geq 3$ in the postoperative period up to $24 \mathrm{~h}$. Complaint of nausea/vomiting was recorded during the same period which was similar to the present study results. Soliman Ramadan Ahmed et al, ${ }^{[8]}$ conducted a study in which wound infiltration with both tramadol and magnesium added to bupivacaine has provided a better pain control compared with bupivacaine alone. Visual analog scale values were significantly higher in group I than groups II and III at $4 \mathrm{~h}$. First dose of supplemental analgesic was later in group III in comparison with groups II and I. Pethidine consumption was lowest in group III compared with the other two groups. Van den Berg AA et al9; reported that during recovery from anaesthesia, emesis and antiemetic requirements were similar and infrequent in each group, during the first $24 \mathrm{~h}$ after surgery, the incidences of nausea alone ( 3 to $5 \%$ ), vomiting alone (17 to $31 \%$ ), and nausea with vomiting (10 to $22 \%$ ). However, any complaint of PONV was least frequent in the saline and pethidine groups (32\% and $37 \%$, respectively) and most frequent in the tramadol and nalbuphine groups $(49 \%$ and $52 \%$, respectively; $\mathrm{P}<0.05$ versus saline, both comparisons; $\mathrm{P}=$ 
NS versus pethidine, both comparisons). The times to onset and severity of PONV were similar in each group, but patients given nalbuphine most frequently $(\mathrm{P}<0.025)$ needed rescue antiemetic to treat PONV. In each group, headache occurred with similar frequency. Mercadante $S$ et $\mathrm{al}^{[10]}$; observed that between the groups, no differences in the use of rescue dose of oral tramadol were observed. Between the two treatments, no differences in pain intensity and relief scores, or in other symptoms were observed. In treatment efficacy as judged by the clinician $(\mathrm{P}=0.73)$, in patient compliance $(\mathrm{P}=0.35)$, or in patient satisfaction regarding treatment $(\mathrm{P}<0.35)$ no differences were found. In adverse effects no differences were found between the two treatments (25.5\%, 13 patients, and 20.4\%, 11 patients, with oral and rectal treatment, respectively). Oral administration for both physicians $(\mathrm{P}=0.0002)$ and patients $(\mathrm{P}=0.002)$ were preferred.

\section{Conclusion}

This study concludes that rectally administering tramadol is safer, easier, more reliable, non-invasive, more comfortable and painless compared to intravenously administered tramadol. In the rectally administered tramadol, the analgesia duration is prolonged which further reduces the rescue analgesia requirement. Compared to intravenously administered tramadol, patient comfort is more in rectally administered tramadol as nausea and vomiting postoperatively is avoided.

\section{References}

1. Eggars KA, Power I. Tramadol. Br J Anaesth. 1995;74:247-9.

2. Driessen B, Reimann W. Interaction of the central analgesic, tramadol, with the uptake and release of 5-hydroxytryptamine in the rat brain in vitro. Br J Pharmacol. 1992;105:147-51.

3. Lee CR, Mc Tavish D, Sorkin EM. Tramadol: A preliminary review of its pharmacodynamic and pharmacokinetic properties and therapeutic potential in acute and chronic pain states. Drugs. 1993;46:313-40.

4. Raffa RB, Friderichs E, Reimann W, Shank RP, Codd EE, Vaught JL. Opioid and nonopioid components independentely contribute to the mechanism of action of tramadol.An atypical opioid analgesic. J Pharmacol Exp Ther. 1992;260:275-85.

5. Zwaveling J, Bubbers S, van Meurs AH, Schoemaker RC, van Heel IR, Vermeij $\mathrm{P}$, et al. Pharmacokinetics of rectal tramadol in postoperative paediatric patients. Br J Anaesth. 2004;93:224-7.

6. Giorgi M, Del Carlo S, Saccomanni G, Łebkowska-Wieruszewska B, Kowalski CJ. Pharmacokinetics of tramadol and its major metabolites following rectal and intravenous administration $\mathrm{N} Z$ Vet $\mathrm{J}$. 2009;57:146-52.

7. Gadani HN, Chaudhary VP; Comparative study of the analgesic efficacy of rectal tramadol versus intravenous tramadol for adult tonsillectomy. Anesth Essays Res. 2010 Jul-Dec;4(2):102-5.

8. Soliman Ramadan Ahmed, Abd El-Raheem Mostafa Dowidar, Ashraf Al Sayed Al Zeftawy, Sameh Mohamed Fathy Ramadan SN, AD Mostafa, AA Al Sayed, SF Mohamed; A comparative study on the analgesic effect of tramadol or magnesium sulfate added to bupivacaine infiltration for postoperative pain management after lumbar disk surgeries; Tanta Medical Journal; 2018,vol.46, issue 3, 203-209.

9. Van der Berg AA, Halliday E, Lule EK, Baloch MS; The effects of tramadol on postoperative nausea, vomiting and headache after ENT surgery. A placebo-controlled comparison with equipotent doses of nalbuphine and pethidine. Acta Anaesthesiol Scand. 1999, Jan; 43(1):28-33.

10. Mercadante S, Arcuri E, Fusco F, Tirelli W, Villari P, Bussolino C, et al. Randomized double-blind, double-dummy crossover clinical trial of oral tramadol versus rectal tramadol administration in opioid-naïve cancer patients with pain. Support Care Cancer. 2005;13:702-7.

Copyright: (c) the author(s), publisher. Academia Anesthesiologica International is an Official Publication of "Society for Health Care \& Research Development". It is an open-access article distributed under the terms of the Creative Commons Attribution Non-Commercial License, which permits unrestricted non-commercial use, distribution, and reproduction in any medium, provided the original work is properly cited.

How to cite this article: Cherayath JB, George J. Comparative Study of the Analgesic Efficacy of Rectal Tramadol versus Intravenous Tramadol for Inguinal Hernia Repair Surgery. Acad. Anesthesiol. Int. 2019;4(2):304-06.

DOI: dx.doi.org/10.21276/aan.2019.4.2.68

Source of Support: Nil, Conflict of Interest: None declared. 